\title{
Exceptionally strong summer-like zonal wind reversal in the upper mesosphere during winter 2015/16
}

\author{
Gunter Stober $^{1}$, Vivien Matthias ${ }^{1}$, Christoph Jacobi ${ }^{2}$, Sven Wilhelm ${ }^{1}$, Josef Höffner ${ }^{1}$, and Jorge L. Chau ${ }^{1}$ \\ ${ }^{1}$ Leibniz Institute of Atmospheric Physics at the University of Rostock, Schlossstr. 6, 18225 Kuehlungsborn, Germany \\ ${ }^{2}$ Institute for Meteorology, University of Leipzig, Stephanstr. 3, 04103 Leipzig, Germany \\ Correspondence to: Gunter Stober (stober@iap-kborn.de)
}

Received: 12 October 2016 - Revised: 6 April 2017 - Accepted: 10 May 2017 - Published: 12 June 2017

\begin{abstract}
The 2015/16 Northern Hemisphere winter season was marked by peculiarities in the circulation pattern in the high-latitude mesopause region. Wind measurements from the Andenes $\left(69^{\circ} \mathrm{N}, 13^{\circ} \mathrm{E}\right)$ meteor radar show westward winds below $84 \mathrm{~km}$ and eastward winds above. This wind pattern in the zonal wind was observable between the end of December 2015 and the end of January 2016, i.e., conditions that are typical for the summer were found during winter. Additional meteor radar measurements at midlatitude stations did not show such a zonal wind reversal but indicate, together with the polar latitude stations, a reversal of the horizontal temperature gradient. This is confirmed by global satellite measurements. Therefore, it is plausible that the polar latitude summer-like zonal wind reversal in DecemberJanuary is in accordance with the reversed horizontal temperature gradient assuming a thermal wind balance between mid- and polar latitudes. The reversed horizontal temperature gradient itself is induced by stationary planetary waves at lower and midlatitudes in the mesosphere, leading to a weakening of the residual circulation above the European sector.
\end{abstract}

Keywords. Meteorology and atmospheric dynamics (middle atmosphere dynamics)

\section{Introduction}

The Northern Hemisphere winter season (November to March) is usually dominated by eastward winds in the middle atmosphere (e.g., Manson and Meek, 1991; Hoffmann et al., 2002; Jacobi et al., 2009; Xu et al., 2011; Matthias et al., 2012). The strongest eastward winds occur around the stratopause. However, sometimes this eastward wind reverses in the mesosphere and stratosphere due to plan- etary waves (PWs) interacting with the background wind (Matsuno, 1971; Andrews et al., 1987) and sometimes this coupling causes so-called sudden stratospheric warmings (SSWs), first detected by Scherhag (1952), when the zonal wind reverses in the whole middle atmosphere for a few days, which also holds for the mesosphere lower thermosphere (MLT) (e.g., Scherhag, 1952; Gregory and Manson, 1975; Cevolani, 1989; Jacobi et al., 1997, 2003; Hoffmann et al., 2007; Matthias et al., 2013; Limpasuvan et al., 2016). A recent review using SD-WACCM can be found in Chandran et al. (2014). In addition to the planetary waves, the zonal wind in the middle atmosphere is also driven by gravity waves and tides. The amplitude of these waves becomes larger with increasing altitude due to the decreasing pressure and density.

The Arctic polar vortex in early winter $2015 / 16$ was unusually cold and strong compared to previous years (Matthias et al., 2016). Here we are going to focus on another unusual feature observed by meteor radar (MR) observations in the polar mesosphere in December-January of the same winter. The dominating eastward wind in the middle atmosphere is reversed to westward winds below $84-82 \mathrm{~km}$ in polar latitudes (around $69^{\circ} \mathrm{N}$ ) without the occurrence of the typical stratospheric SSW signature (after World Meteorological Organization (WMO) definition, see e.g., Chandran et al., 2014). The exceptionally strong summer-like upper mesospheric zonal wind reversal started at the end of December 2015 and lasted for 4 weeks until the end of January 2016. Further on we are going to call this wind pattern summer-like mesospheric zonal winds. We associate this unusual wind regime at altitudes between 70 and $80 \mathrm{~km}$ with geostrophic and thermal wind balance due to a large-scale meteorological circulation pattern leading to a weakening of 
Table 1. Experimental setup for the three meteor radars used in this study.

\begin{tabular}{lrrr}
\hline Parameter & Andenes & Juliusruh & Collm \\
\hline PRF (Hz) & 625 & 625 & 625 \\
Peak power (kW) & 30 & 30 & 7.5 \\
Frequency (MHz) & 32.55 & 32.55 & 36.2 \\
Antenna & crossed & crossed & linear \\
Code & 7-bit Barker & 7-bit Barker & 7-bit Barker \\
Range resolution (km) & 1.5 & 1.5 & 1.5 \\
\hline PRF is pulse repetition frequency. PRF and code settings changed at Juliusruh \\
(January 2014), Andenes (May 2014), Collm (June 2015).
\end{tabular}

the residual circulation (Kinoshita et al., 2010) within the polar cap above the European sector.

In this paper we investigate this peculiarity of the winter 2015/16 by combining local MR wind and temperature measurements at Andenes (69.1 $\left.{ }^{\circ} \mathrm{N}, 13.0^{\circ} \mathrm{E}\right)$, Juliusruh $\left(54.7^{\circ} \mathrm{N}\right.$, $\left.13.3^{\circ} \mathrm{E}\right)\left(\right.$ Stober et al., 2012) and Collm $\left(51.3^{\circ} \mathrm{N}, 13.0^{\circ} \mathrm{E}\right)$ (Jacobi et al., 2007) with global satellite observations. The temperature measurements of the Andenes MR are confirmed by nearby Fe-lidar observations conducted at ALOMAR $\left(69.1^{\circ} \mathrm{N}, 13.0^{\circ} \mathrm{E}\right)$. In total $292 \mathrm{~h}$ of lidar observations were gathered from December to March 2016.

The ground-based instruments are complemented by satellite observations. We use the Microwave Limb Sounder (MLS) measurements onboard the AURA satellite, which provides a global data set for the stratosphere and mesosphere (Schwartz et al., 2008; Livesey et al., 2015). In particular, we assess the latitudinal and longitudinal changes induced by stationary PWs.

Section 2 provides a description of the MR wind and temperature measurements, as well as a short summary of the Fe-lidar temperatures and an overview of the MLS data. The peculiarity of the Northern Hemisphere winter 2015/16 is described and compared to normal winter conditions in Sect. 3. These results are discussed in light of planetary wave activity in Sect. 4 and concluded in Sect. 5.

\section{Description of the observations and methods}

\subsection{Meteor radar observation and wind analysis}

In this study we present observations of three meteor radars located at Andenes $\left(69.3^{\circ} \mathrm{N}, 16.0^{\circ} \mathrm{E}\right)$, Juliusruh $\left(54.6^{\circ} \mathrm{N}\right.$, $\left.13.3^{\circ} \mathrm{E}\right)$ and Collm $\left(51.3^{\circ} \mathrm{N}, 13.0^{\circ} \mathrm{E}\right)$. The experiment settings and technical specifications of each system can be found in Table 1. A more detailed description of the basic analysis software with regard to the meteor detection and radial velocity determination is given in Hocking et al. (2001).

The meteor radar winds are computed applying a modified version of the so-called all-sky fit (Hocking et al., 2001). We obtain hourly winds by shifting a $2 \mathrm{~h}$ window by $1 \mathrm{~h}$. Each meteor within the window is weighted by its statistical uncertainty and by its temporal distance from the center of the window using a Gaussian kernel. A similar procedure is applied to account for altitude offsets between the observation and the altitude where we reference our wind analysis. We use a $3 \mathrm{~km}$ altitude kernel centered at the reference altitude shifted by $2 \mathrm{~km}$.

To further enhance the altitude coverage and to remove outliers or erratic data from our measurements, we include additional constraints in our wind analysis. In particular, at the upper and lower edges of the meteor layer, the number of meteor detections is low and their spatial distribution may introduce difficulties in estimating both horizontal wind components with a reasonable error. Therefore, we implemented a regularization accounting for the gradients in space (vertical), $\frac{\mathrm{d} u}{\mathrm{~d} z}=$ const, $\frac{\mathrm{d} v}{\mathrm{~d} z}=$ const and $\frac{\mathrm{d} w}{\mathrm{~d} z}=$ const, as well as in time, $\frac{\mathrm{d} u}{\mathrm{~d} t}=$ const, $\frac{\mathrm{d} v}{\mathrm{~d} t}=$ const and $\frac{\mathrm{d} w}{\mathrm{~d} t}=$ const. The gradients are estimated for each time and altitude bin using the local derivative of the neighbor bins in space and time. At least two neighbors with a reliable wind measurement are required, which ensures a proper upper and lower boundary and no extrapolation of the winds without a sufficient number of measurements. Furthermore, we put a constraint on the vertical velocity to be $w \approx 0$, which appears to be reasonable, considering the observational diameter of $425 \mathrm{~km}$ at $90 \mathrm{~km}$ altitude and the integration period. Using these additional constraints in the wind analysis allows the use of only four meteors to obtain mean winds with a still acceptable error and we reduced the impact of erratic data or outliers on the obtained winds.

Due to the regularization, the wind computation is more complex and requires an iterative scheme. First we compute an initial guess of the winds for all altitudes and each time step (typically $24 \mathrm{~h}$ plus $1 \mathrm{~h}$ before and after). Based on this initial guess we estimate the gradient terms for each wind component and derive a new solution, which now includes the regularization constraints. We repeat this procedure until our wind solution does not show a significant change anymore. Usually not more than five iterations are needed.

The statistical uncertainties in the horizontal winds, applying the procedure described above and using the full error propagation from the radial velocity, range within $1-5 \mathrm{~m} \mathrm{~s}^{-1}$. The largest statistical uncertainties are observed at the upper and lower edges of the meteor layer. In general the statistical uncertainties tend to become larger when fewer meteors are included in the wind fit. A more detailed comparison of the obtained MR winds with the Navy Global Environmental Model (NAVGEM) is given in McCormack et al. (2016).

The hourly winds obtained are further analyzed to derive the tidal amplitudes and mean winds. Therefore, we decompose our measured winds into mean zonal and meridional winds $u_{0}, v_{0}$ and diurnal, semidiurnal and terdiurnal tidal components using the following approach: 


$$
\begin{aligned}
u, v & =u_{0}, v_{0}+\sum_{n=1}^{3} a_{n} \sin \left(2 \pi / T_{n} \cdot t\right) \\
& +b_{n} \cos \left(2 \pi / T_{n} \cdot t\right) .
\end{aligned}
$$

Here $T_{n}$ takes values of 24,12 and $8 \mathrm{~h}$ to account for the three tidal components and $a_{n}, b_{n}$ are coefficients of the tidal amplitude for each wind component.

In this study we focus on mean winds during the winter season 2015/16. Thus, we determined the mean zonal and meridional winds as well as the tidal amplitudes using a 3day average centered at the respective day.

The mean winds are obtained using a newly developed adaptive spectral filter, which uses a sliding window of a predefined length and fits the tidal amplitudes for each tidal component accounting for the number of wave cycles within the window. In a first step we fit for the mean wind and diurnal, semidiurnal and terdiurnal tides using, for example, a $24 \mathrm{~h}$ window. Then we subtract the mean wind component and the diurnal tide from our observations and fit the residual with a $12 \mathrm{~h}$ window centered at the respective time to estimate the semidiurnal tide. A similar procedure is then applied to estimate the terdiurnal tidal amplitude with an $8 \mathrm{~h}$ window. This results in a time series with a $1 \mathrm{~h}$ resolution for the mean winds and the diurnal, semidiurnal and terdiurnal tides, which is then subtracted from our hourly wind observations. The gravity wave (GW) activity is mainly given by the residuum and contains all fluctuations different than the tides or planetary waves.

\subsection{Temperature measurements by lidar and meteor radar}

Since July 2014 we have obtained MLT temperature profiles with a mobile scanning Fe lidar at ALOMAR (Höffner and Lautenbach, 2009). The system uses a two-wavelength $(772 \mathrm{~nm}$ and $386 \mathrm{~nm})$ alexandrite laser, one at the Dopplerbroadened iron resonance line and the other one at twice the frequency of the iron resonance. The system has full daylight capabilities and is hence suitable for performing continuous temperature observations at the MLT as long as the tropospheric weather situation permits it. A more detailed description of the lidar and iron chemistry is given in Lübken et al. (2015) and Viehl et al. (2015).

The typical statistical uncertainty of the temperature measurement is $< \pm 5 \mathrm{~K}$ with a $1 \mathrm{~h}$ integration and a $1 \mathrm{~km}$ vertical resolution. However, the altitude coverage and the possibility of inferring temperatures from the iron layer at the MLT depends on the Fe densities and their vertical distribution as well as the temporal evolution of the layer (Viehl et al., 2015). In winter high iron number densities often allows temperature measurements with $\pm 1 \mathrm{~K}$ at the peak of the layer, which is close to $88 \mathrm{~km}$ altitude.
During January 2016 we had a rather unique weather situation above northern Norway with long-lasting cloud-free conditions for several successive days. Thus, we were able to conduct a temperature comparison with our MR observations. Therefore, we computed a $24 \mathrm{~h}$ mean temperature value from the hourly lidar data and determined the geophysical variability by estimating the variance for each $24 \mathrm{~h}$ period. The continuity of the lidar temperature observation ensured that the daily mean value was unbiased with regard to the tides, which is essential as we want to compare it to a daily mean temperature from the MR.

Another technique to estimate the mesopause temperature uses the ambipolar diffusion of meteor trails (Tsutsumi et al., 1994; Hocking et al., 1997, 2001; Stober et al., 2008). This technique requires a calibration to remove, for example, the effect of ice (summer mesopause at polar latitudes) and dust ambient to the meteor trail on the decay time (Singer et al., 2008), which is of particular relevance below $82-84 \mathrm{~km}$ in summer. A first comparison of lidar and MR temperatures applying the outlined procedure can be found in Stober et al. (2012).

Our MR temperatures are derived by using the method described in (Hocking et al., 1997). However, we consider the temperature gradient as calibration constant, as we have no direct possibility to obtain it from our observations and the exceptionally strong summer-like upper mesospheric zonal wind reversal is not well represented in empirical models like, NRLMSISE-00 (Picone et al., 2002). Thus, our absolute MR temperatures are tuned to fit the lidar and seasonal mean MLS satellite observations. The relative temperature variation is not affected by this procedure. We basically debias and calibrate our absolute temperatures using a seasonal reference from November 2015 to March 2016.

\subsection{Microwave Limb Sounder}

To compare the local measurements with global observations and to perform a planetary wave analysis, we use temperature and geopotential height data from MLS onboard the Aura satellite (Waters et al., 2006; Livesey et al., 2015). MLS has a global coverage from $82^{\circ} \mathrm{S}$ to $82^{\circ} \mathrm{N}$ on each orbit and a useful height range from approximately 11 to $97 \mathrm{~km}(261-$ $0.001 \mathrm{hPa}$ ) with a vertical resolution of $\sim 4 \mathrm{~km}$ in the stratosphere and $\sim 14 \mathrm{~km}$ at the mesopause. The temporal resolution is 1 day at each location and data are available from August 2004 until today (Livesey et al., 2015). Version 4 MLS level 2 data are used and the recommended quality screening procedures of Livesey et al. (2015) have been applied. To estimate the PWs we used the same analysis as described in Matthias et al. (2012). 


\section{Summer-like mesospheric zonal winds in the Northern Hemisphere winter 2015/16}

Figure 1 shows a composite of the seasonal pattern of the daily zonal and meridional winds in the mesosphere above Andenes, which is also qualitatively representative for midlatitude stations. The zonal wind shows the characteristic seasonal pattern with weak eastward winds in winter, which then reverses in spring (March-April) into a weak westward wind at all altitudes (e.g., Hoffmann et al., 2010; Xu et al., 2011; Manney et al., 2008). Towards the summer months a strong wind shear occurs with eastward winds above $85-93 \mathrm{~km}$ and a strong westward jet below. At the end of the summer (late August-September) the circulation regime changes to a weak eastward wind at all altitudes. The major difference between the polar and midlatitudes is given by the height of the summer wind reversal. At midlatitudes the wind reversal occurs at $1-2 \mathrm{~km}$ lower altitudes (Hoffmann et al., 2010). The meridional wind component shows a weaker seasonal pattern with a small southward wind enhancement in summer, at altitudes where the zonal wind shear occurs.

Figure 2 shows the time series of the zonal and meridional wind at Andenes, Juliusruh and Collm in winter 2015/16. At polar latitudes we found a wind reversal in the zonal wind at 82-84 km altitude starting at the end of December 2015 and lasting almost a month. We emphasized this period with vertical black lines in Fig. 2. Usually a zonal wind reversal in winter is associated with SSWs. In this case neither the zonal mean zonal wind nor the temperature gradient at $10 \mathrm{hPa}$ at $60^{\circ} \mathrm{N}$ are reversed (not shown, WMO definition of minor and major SSW; see Chandran et al., 2014). Thus, the observed mesospheric zonal wind reversal cannot be associated with an ongoing SSW. The midlatitude stations are characterized by typical planetary wave activity throughout the winter season and do not indicate such a reversal in the wind. The period of the summer-like mesospheric zonal winds at Andenes is followed by two minor SSWs (no wind reversal at $10 \mathrm{hPa}$ but a reversed temperature gradient at $10 \mathrm{hPa}$ ), which are not subject of this study and will therefore not be further discussed.

Figure 3 shows a comparison of the vertical structure of the zonal wind above Andenes for a typical summer (blue), a typical winter January profile (green) averaged from 2002 to 2016 and a mean vertical profile (red) averaged from 26 December 2015 to 5 January 2016. The mean summer and January profiles are computed using the complete available data set for the Andenes MR. The error bars for the mean summer profile (blue) represent the geophysical variability, which is also representative for the other two profiles. To underline the statistical significance of the exceptional zonal wind profile the error bars of the other two profiles (mean January 2016, red; and climatological mean January, green) show the statistical uncertainties, which are representative for the other profiles as well. However, we have to note that the geophysical variability is approximately of the order of $15-20 \mathrm{~m} \mathrm{~s}^{-1}$
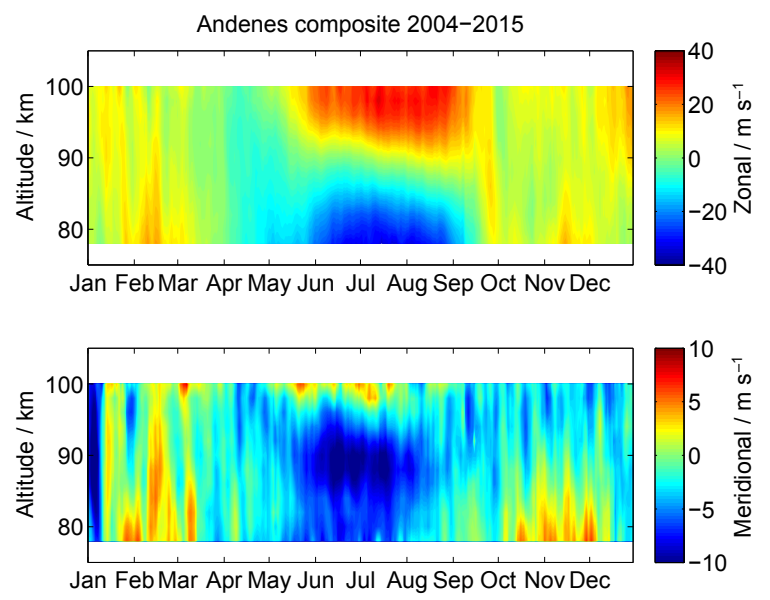

Figure 1. Composite of the zonal and meridional winds above the Andenes MR. The composite is computed averaging all measurements between 2003 and 2016.

for all three profiles and altitudes. The mean January profile (green line) indicates almost no vertical variability and shows constant wind speeds between 5 and $6 \mathrm{~m} \mathrm{~s}^{-1}$. This is understandable as most of the variability during the winter season is due to the presence of PWs, which have long vertical wavelengths and more or less disappear by averaging over the winter months (December, January and February). The summer profile (JJA - June, July and August) shows a strong gradual increase in the wind speed from -30 up to $20 \mathrm{~m} \mathrm{~s}^{-1}$ at $98 \mathrm{~km}$ and decreases above this height. The zero line transition occurs at approximately $87-89 \mathrm{~km}$ altitude. The vertical zonal wind profile of the summer-like condition is vertically shifted compared to the mean summer circulation. The zero line crossing occurs at $79 \mathrm{~km}$ altitude and the wind maximum is reached at approximately $90 \mathrm{~km}$. Above $90 \mathrm{~km}$ the zonal wind remains nearly constant before it starts to decrease again above $95 \mathrm{~km}$. In principle the vertical profile looks rather similar to the mean summer circulation regime, but is shifted by $10 \mathrm{~km}$ to lower heights. The westward winds below $79 \mathrm{~km}$ are confirmed by geostrophic winds (cyan) around Andenes $\left(67-72^{\circ} \mathrm{N}, 0-30^{\circ} \mathrm{E}\right)$ calculated from MLS geopotential height data (Andrews et al., 1987). The geopotential altitudes were corrected in the mesosphere to ensure a more reliable comparison to the MR profiles. The difference between geopotential height and geometric altitude can be as large as $5 \mathrm{~km}$ for the uppermost MLS levels. Above $85 \mathrm{~km}$ altitude the obtained geostrophic winds show larger discrepancies compared to the local radar observations. We attribute these differences to the temperature and geopotential height retrieval of MLS, which tend to have a larger bias and uncertainty for geopotential heights above $85-87 \mathrm{~km}$ (Schwartz et al., 2008).

The temporal evolution of the mesospheric temperature at $88 \mathrm{~km}$ altitude is shown in Fig. 4 for all three MRs and the Fe lidar. At the midlatitude stations of Juliusruh and Collm 

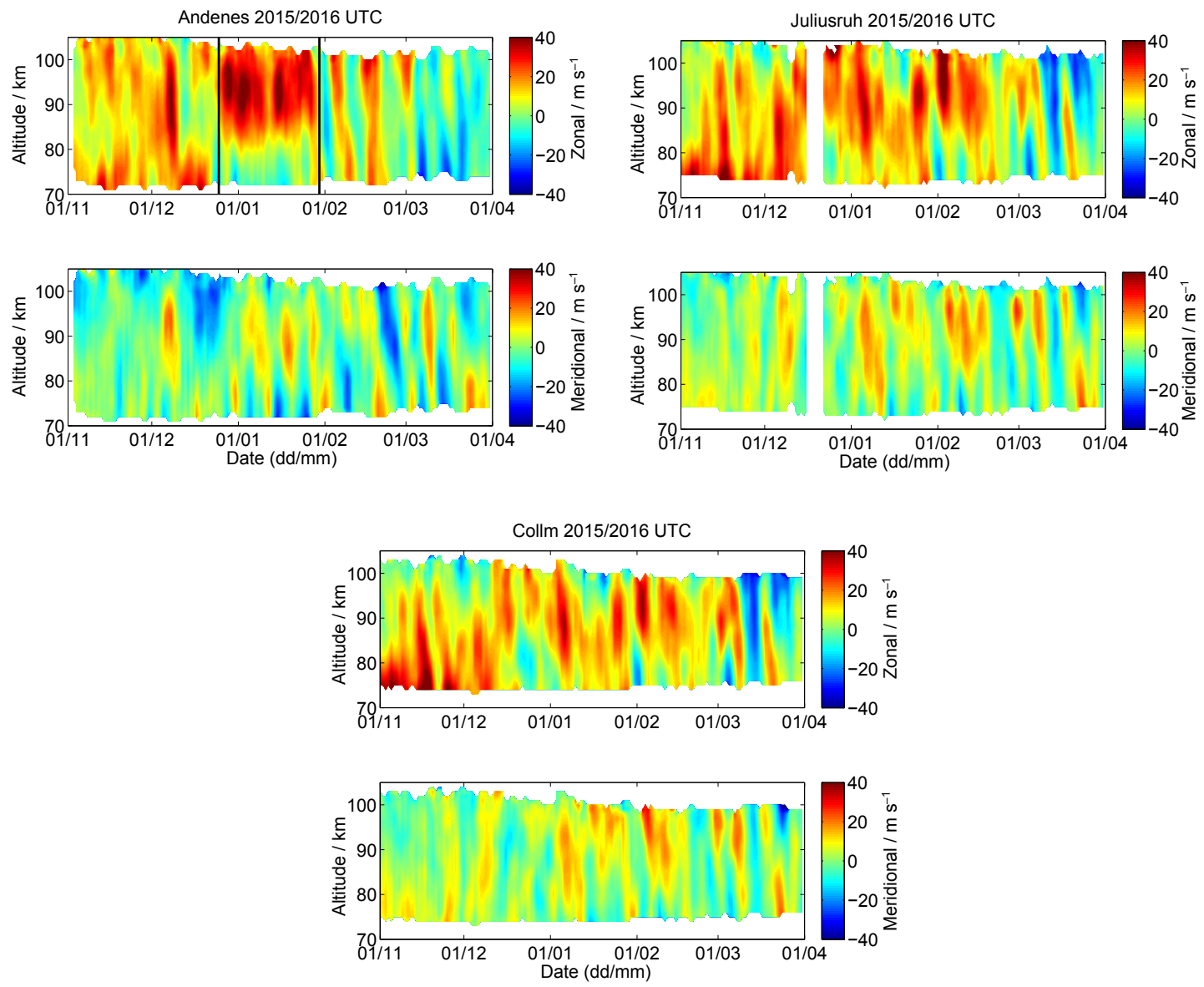

Figure 2. Zonal and meridional winds during the winter season, November 2015 until March 2016, at three different locations after the removal of potential tidal and GW contributions using the adaptive spectral filter described to decompose the time series.

we observe a rather normal situation throughout the winter, with temperatures ranging from 180 to $220 \mathrm{~K}$. The temperature time series shows some modulation due to the presence of PWs, whereas the temperature above Andenes indicates a major difference compared to the midlatitude stations. At Andenes the temperature drops from the typical winter values of 190-210 K to approximately $170 \mathrm{~K}$ in December and remains significantly lower until the minor SSW at the end of January. Finally, after mid-February the mesosphere temperature reaches similar values at all three stations. At this time the transition towards the summer circulation regime had already started.

The green data points in Fig. 4 represent measurements with the Fe lidar at ALOMAR co-located to the Andenes MR. Although the temporal resolution of the Fe lidar could be better than $1 \mathrm{~h}$, we processed the data similar to the MR to obtain a $24 \mathrm{~h}$ median temperature and a temperature variability within each $24 \mathrm{~h}$ period. This variability contains all waves within the $24 \mathrm{~h}$ window. The weather conditions in January 2016 were good enough to derive daily mean temperatures and a temperature variability for several days from 6 to 19 January 2016. The MR and the Fe lidar are in rea- sonable agreement and show a PW with similar temperature amplitude.

\section{Discussion}

The observed summer-like mesospheric zonal winds during the winter season 2015/16 are unusual. In the following we discuss possible reasons for the observed wind regime at the MLT with regard to gravity waves and planetary waves.

\subsection{The role of gravity waves in the MLT}

The summer time zonal wind reversal in the MLT at midand polar latitudes (see Fig. 1) is attributed to vertically propagating $\mathrm{GW}$, carrying energy and momentum up to the MLT. Depending on the propagation direction and phase speed of the GW and on the zonal wind characteristics, there is a strong filtering effect at different altitudes. The summer stratosphere is characterized by westward winds filtering most of the westward-propagating $\mathrm{GW}$ when the phase speed of the waves is lower than the horizontal wind velocity $u$ and, hence, the GW reach a critical level while upward propagat- 


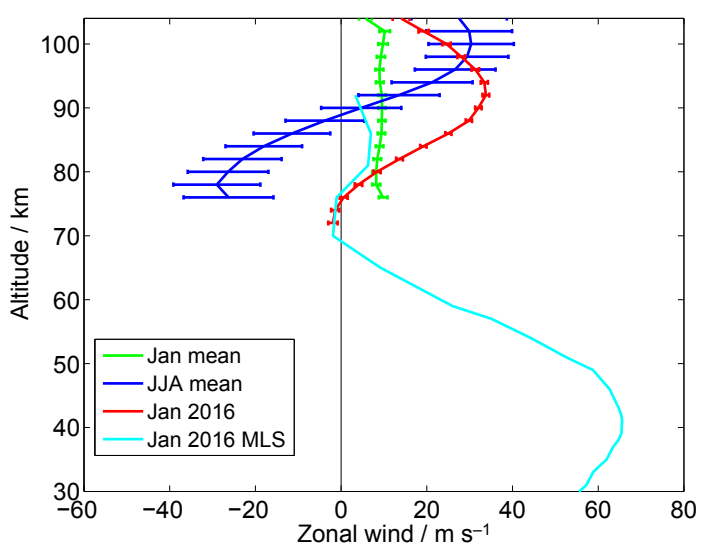

Figure 3. Vertical zonal wind profiles for the mean summer (June, July and August), mean January and for the summer-like conditions averaged between 26 December 2015 and 5 January 2016 at Andenes. The cyan-colored line shows the geostrophic winds derived from MLS around Andenes. The error bars for the mean summer profile show the geophysical variability and are representative for the other two profiles. The error bars given for the mean January (green) and January 2016 profiles are the statistical uncertainties, which are also representative for three profiles.

ing. Eastward-propagating GWs that were generated above the tropospheric jet or were able to penetrate through it can propagate to the MLT without such a critical-level filtering at stratospheric heights. At the MLT region these GWs become instable and deposit eastward-directed momentum onto the mean flow, leading to the observed wind reversal in the summer MLT (e.g., Fritts and Alexander, 2003; Becker, 2012).

In December 2015 and January 2016 the extraordinary strong polar vortex with zonal eastward wind speeds above $50-100 \mathrm{~m} \mathrm{~s}^{-1}$ in the stratosphere should have filtered almost all eastward propagating GW. Considering these high wind speeds in the polar vortex at stratospheric heights and under the assumption that the critical-level filtering is present, the exceptionally strong summer-like upper mesospheric zonal wind reversal is not explainable by eastward-propagating $\mathrm{GW}$ of orographic or tropospheric origin. To what extent secondary GW, generated above the strong polar vortex, may impact the observed zonal wind reversal at the MLT will be investigated in a separate study. We also investigated a potential effect due to the tidal activity. In particular, we found no changes in the total semidiurnal tide activity for the last winter season (data not shown) that could be associated with the observed changes in the zonal wind.

\subsection{Geostrophic and thermal wind balance}

Assuming a thermal wind balance we can associate the vertical wind shear in the zonal wind to a horizontal temperature gradient. Thus, a zonal wind shear or a zonal wind reversal is related to a change in the meridional temperature gradient. Therefore, we estimate the temperature gradient between po-

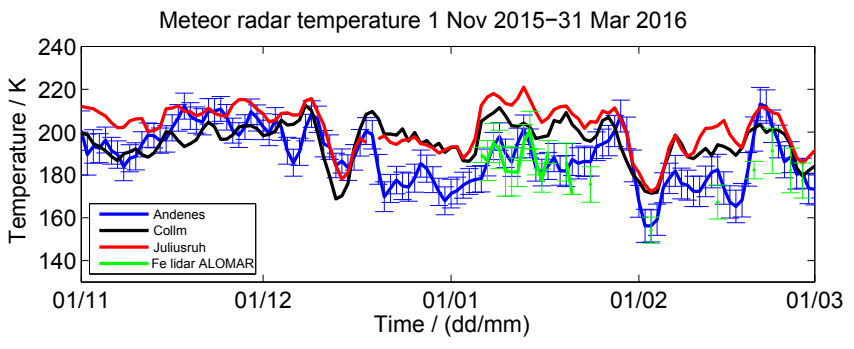

Figure 4. Mesospheric temperatures derived from three MR observations and the ALOMAR Fe-lidar system for the winter season 2015/16. The error bars shown are given by the geophysical variability within $24 \mathrm{~h}$. The temporal resolution of the lidar was decreased to match the coarse resolution of the radar-derived temperatures.

lar and midlatitudes using the temperature information from our MRs in Andenes and Juliusruh. The temperature difference between both stations is approximately $15-20 \mathrm{~K}$ for the time period of the summer-like mesospheric zonal winds at $90 \mathrm{~km}$ altitude. Furthermore, we infer the pressure difference between mid- and polar latitudes by taking into account the neutral air density variation from the meteor ablation altitudes (Stober et al., 2012). Considering the geopotential height difference and the temperatures between Andenes and Juliusruh, we obtain a pressure gradient of $4 \%$ between both stations. Assuming a geostrophic wind balance, this pressure gradient is related to a strong eastward acceleration at approximately $90 \mathrm{~km}$.

But how can we explain the weak westward winds in the mesosphere between 70 to $82 \mathrm{~km}$ altitude, which are partly seen by the Andenes MR and which are reproduced by the MLS-derived geostrophic winds (Fig. 3). The remarkable agreement between the MLS and MR winds above Andenes is already a first indication that the zonal wind reversal is explainable by a geostrophic and thermal wind balance, or in other words by a large-scale meteorological circulation pattern in the mesosphere.

In order to assess the horizontal scale of the meridional thermal gradient, we estimated the horizontal temperature gradient between the mid- and polar latitudes from MLS temperature measurements and the evolution of the gradient over the winter season. This is shown in Fig. 5, where the dashed vertical lines indicate the period of the zonal wind reversal in the mesosphere as observed by the Andenes MR. The temperature gradient is estimated above the European sector $\left(0-30^{\circ} \mathrm{E}\right)$, subtracting the MLS temperatures at $80^{\circ} \mathrm{N}$ from the midlatitudes at $40^{\circ} \mathrm{N}$ for each pressure level. At the stratopause level $(\approx 60 \mathrm{~km})$ there is a positive temperature gradient until the first minor SSW at the end of January, which is representative for a typical winter situation. Due to the zonal-mean residual-circulation-driven downwelling above the winter hemispheric pole area, one expects higher temperatures within the polar cap stratosphere compared to 


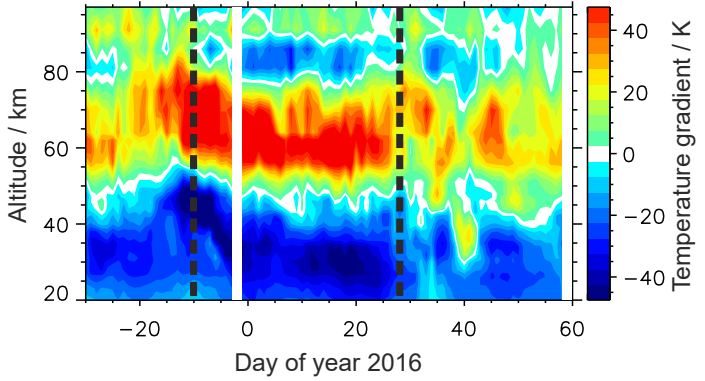

Figure 5. Altitude-time cross section of the meridional temperature gradient between 80 and $40^{\circ} \mathrm{N}$ derived from MLS above the European sector defined as $0-30^{\circ} \mathrm{E}$. The temperature gradient is obtained using bins of $5^{\circ}$ in latitude.

the midlatitude stratosphere (e.g., Becker, 2012; Chandran et al., 2014). Above the stratosphere, we find a reversed temperature gradient, which remains almost persistent from the end of December until the two minor SSWs.

Our observations lead us to two implications. Firstly, during the period of the zonal wind reversal in the mesosphere we observe normal conditions in the stratosphere and lower mesosphere. Typical signatures of an ongoing SSW like the reversed temperature gradient at $10 \mathrm{hPa}$ and an at least weakening of the polar vortex are missing. Conversely, the Arctic polar vortex was unusually cold and strong in early winter 2015/16 (Matthias et al., 2016) and the meridional temperature gradient was not reversed (see Fig. 5). Hence, we observed no indication for an ongoing SSW in the stratosphere. Secondly, the lower mesospheric weak westward winds are accompanied by a meridional flow towards the midlatitudes, weakening the residual circulation (Kinoshita et al., 2010) and, hence, causing a weakening of the downwelling within the polar cap. This is supported by, again, looking at the temperature gradient in Fig. 5, which becomes weaker with time the longer the summer-like circulation lasts at altitudes between 60 and $70 \mathrm{~km}$.

\subsection{The planetary wave activity}

Finally, we diagnose why the exceptionally strong summerlike upper mesospheric zonal wind reversal could occur anyway and be sustained for almost 1 month. Usually the Arctic polar vortex is disturbed by strong PW activity, especially by the stationary PW 1 (SPW1). However, in winter 2015/16 the amplitude of the SPW1 was much lower than usual and thus the polar vortex was barely disturbed (Matthias et al., 2016). This strong polar vortex lead to a shift of the PW activity towards midlatitudes. This is shown in Fig. 6 where we compare the climatological amplitude of the SPW1 and SPW2 (black contours) with the activity observed during the winter season 2015/16 (colored contour). At the beginning of the summer-like mesospheric zonal winds (21 December 20155 January 2016) the SPW1 was the dominating wave, but
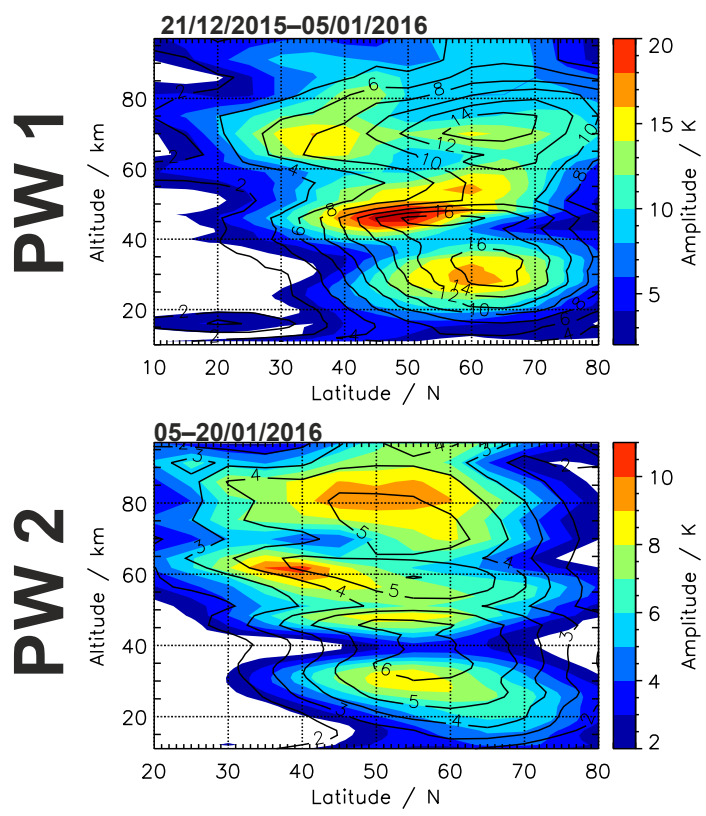

Figure 6. Altitude-latitude cross section of the amplitude of the SPW1 and SPW2 derived from MLS geopotential height data. The plot shows the average amplitude of the SPW1 and SPW2 during the period of summer-like conditions as colored contours. The black contours show the mean activity of the SPW1 using the MLS data between 2005 and 2016 .

later (6-20 January 2016) the SPW2 took over. Below $40 \mathrm{~km}$ the SPW1 behaved more or less like the climatological mean. Between 40 and $60 \mathrm{~km}$ the area with the maximum amplitude of the SPW1 was shifted by $10^{\circ}$ towards midlatitudes. However, above $60 \mathrm{~km}$ there is a clear deviation of the SPW1 amplitude from the climatology. The area with the maximum amplitude is shifted from $60-70$ to $30-40^{\circ} \mathrm{N}$, which is a displacement by $30^{\circ}$ and only weak amplitudes are visible at polar latitudes. Similar to the SPW1, we also observe a shift, compared to the climatology, of the SPW2 towards lower latitudes at the stratopause. In the mesosphere the SPW2 seems to be amplified and shifted to higher altitudes in relation to the climatology.

That there was an anomalous southward-shifted wave activity during the winter season 2015/16 is also reflected by the Eliassen-Palm (EP) fluxes. Matthias et al. (2016) shows the EP flux in the stratosphere for NovemberDecember 2015, which is qualitatively representative for January 2016 as well (not shown).

Another interesting aspect of the SPW1 activity is its phasing. Our local observations were on a rather beneficial location with respect to the warm and cold phases of the SPW1. In Fig. 7 we show a longitude vs. latitude contour plot of the SPW1 at $80 \mathrm{~km}$ altitude. The wave activity leads to warmer temperatures above the midlatitude European sector compared to the low temperatures within the polar cap in the mesosphere. Due to the stable polar vortex the phase of the 


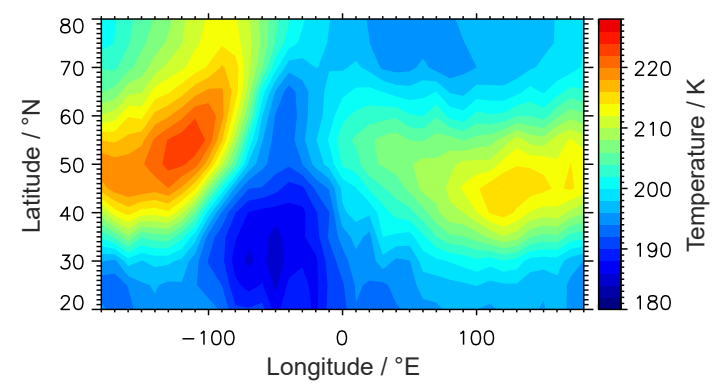

Figure 7. Latitude-longitude cross section of MLS temperatures at $80 \mathrm{~km}$ altitude. The picture is a composite of all MLS observations gridded to latitude and longitude bins averaged for the time between 21 December 2015 and 5 January 2016.

SPW1 was constant and thus the reversed meridional temperature gradient was sustained for almost 1 month until the end of January. The increasing activity of the SPW2 in January (not shown here) did not lead to a mitigation of the temperature gradient in the European sector. The phases the SPW1 and SPW2 sustained the temperature gradient until the end of January 2016 above the European sector.

\section{Conclusions}

During the winter season 2015/16 we observed an exceptionally strong summer-like upper mesospheric zonal wind reversal at polar latitudes with westward winds below $82 \mathrm{~km}$ and eastward winds above lasting for almost a month. We call this unusual wind reversal summer-like mesospheric zonal wind since it is similar to the summer zonal wind reversal and no signature of a SSW was observed in the stratosphere (after WMO definition). We presented a diagnosis of the meteorological situation in the mesosphere above the European sector using local MR and lidar observations complemented with global satellite data.

The remarkable agreement between the MR and the geostrophic winds obtained from MLS lets us conclude that the mesospheric zonal wind reversal, which we herein called summer-like mesospheric zonal winds, is associated with a geostrophic and thermal wind balance. As a consequence of the westward zonal wind between 70 and $80 \mathrm{~km}$ the residual circulation was weakened at these altitudes, leading to the observed cooling within the polar cap accompanied by a meridional flow from the polar region towards the midlatitudes in the European sector.

The exceptionally strong summer-like upper mesospheric zonal wind reversal was caused by an unusually high SPW1 and SPW2 amplitude in low latitudes, leading to a reversal of the meridional temperature gradient over the European sector in the upper mesosphere. In accordance with the geostrophic and thermal wind balance, a reversed zonal wind was observed between 70 and $80 \mathrm{~km}$ in Andenes. Due to the stable polar vortex in this winter, a constant phasing of the
SPW1 and SPW2, and a favorable location of the MR, the summer-like mesospheric zonal winds were sustained for almost 1 month.

Data availability. The lidar data are available upon request from Josef Höffner. To access the Collm meteor radar data please contact Christoph Jacobi. The Andenes and Juliusruh meteor radar data are available upon request from Gunter Stober.

Competing interests. The authors declare that they have no conflict of interest.

Acknowledgements. We acknowledge the technical support of Falk Kaiser from Leipzig University and the IAP technicians. We are grateful for the discussions with Christoph Zülicke and Peter Hoffmann. Christoph Jacobi acknowledges the support from the SFB/TR 172 in project D01 funded by the Deutsche Forschungsgemeinschaft (DFG). Furthermore, we want to thank Axel Gabriel for his help in deriving MLS winds and EP flux. This work was partially supported by the WATILA project (SAW-2015-IAP-1). We thank the Jet Propulsion Laboratory, NASA for providing access to the Aura/MLS level 2 retrieval products downloaded from http://mirador.gsfc.nasa.gov.

The topical editor, Andrew J. Kavanagh, thanks the two anonymous referees for help in evaluating this paper.

\section{References}

Andrews, D. G., Holton, J. R., and Leovy, C. B.: Middle atmosphere dynamics, Academic Press, New York, NY, USA, 489 pp., 1987.

Becker, E.: Dynamical Control of the Middle Atmosphere, Space Sci. Rev., 168, 283-314, https://doi.org/10.1007/s11214-0119841-5, 2012.

Cevolani, G.: Long period waves in the middle atmosphere: Response of mesospheric and thermospheric winds to recent minor stratospheric warmings at mid-latitudes, Ann. Geophys., 7, 451 $-458,1989$.

Chandran, A., Collins, R., and Harvey, V.: Stratospheremesosphere coupling during stratospheric sudden warming events, Adv. Space Res., 53, 1265-1289, https://doi.org/10.1016/j.asr.2014.02.005, 2014.

Fritts, D. and Alexander, M. J.: Gravity wave dynamics and effects in the middle atmosphere, Rev. Geophys., 41, 1-64, https://doi.org/10.1029/2001RG000106, 2003.

Gregory, J. B. and Manson, A. H.: Winds and Wave Motions to $110 \mathrm{~km}$ at Mid-Latitudes. III. Response of Mesospheric and Thermospheric Winds to Major Stratospheric Warmings, J. Atmos. Sci., 32, 1676-1682, https://doi.org/10.1175/15200469(1975)032<1676:WAWMTK>2.0.CO;2, 1975.

Hocking, W., Fuller, B., and Vandepeer, B.: Real-time determination of meteor-related parameters utilizing modern digital technology, J. Atmos. Sol.-Terr. Phy., 63, 155-169, https://doi.org/10.1016/S1364-6826(00)00138-3, 2001. 
Hocking, W. K., Thayaparan, T., and Jones, J.: Meteor decay times and their use in determining a diagnostic mesospheric Temperature-pressure parameter: Methodology and one year of data, Geophys. Res. Lett., 24, 2977-2980, https://doi.org/10.1029/97GL03048, 1997.

Hoffmann, P., Singer, W., and Keuer, D.: Variability of the mesospheric wind field at middle and Arctic latitudes in winter and its relation to stratospheric circulation disturbances, J. Atmos. Sol.-Terr. Phy., 64, 1229-1240, https://doi.org/10.1016/S13646826(02)00071-8, 2002.

Hoffmann, P., Singer, W., Keuer, D., Hocking, W., Kunze, M., and Murayama, Y.: Latitudinal and longitudinal variability of mesospheric winds and temperatures during stratospheric warming events, J. Atmos. Sol.-Terr. Phy., 69, 2355-2366, https://doi.org/10.1016/j.jastp.2007.06.010, 2007.

Hoffmann, P., Becker, E., Singer, W., and Placke, M.: Seasonal variation of mesospheric waves at northern middle and high latitudes, J. Atmos. Sol.-Terr. Phy., 72, 1068-1079, https://doi.org/10.1016/j.jastp.2010.07.002, 2010.

Höffner, J. and Lautenbach, J.: Daylight measurements of mesopause temperature and vertical wind with the mobile scanning iron lidar, Opt. Lett., 34, 1351-1353, https://doi.org/10.1364/OL.34.001351, 2009.

Jacobi, C., Schminder, R., and Kürschner, D.: The winter mesopause wind field over Central Europe and its response to stratospheric warmings as measured by LF D1 wind measurements at Collm, Adv. Space Res., 20, 1223-1226, 1997.

Jacobi, C., Kürschner, D., Muller, H., Pancheva, D., Mitchell, N., and Naujokat, B.: Response of the mesopause region dynamics to the February 2001 stratospheric warming, J. Atmos. Sol.-Terr. Phy., 65, 843-855, https://doi.org/10.1016/S13646826(03)00086-5, 2003.

Jacobi, C., Fröhlich, K., Viehweg, C., Stober, G., and Kürschner, D.: Midlatitude mesosphere/lower thermosphere meridional winds and temperatures measured with meteor radar, Adv. Space Res., 39, 1278-1283, https://doi.org/10.1016/j.asr.2007.01.003, 2007.

Jacobi, C., Fröhlich, K., Portnyagin, Y., Merzlyakov, E., Solovjova, T., Makarov, N., Rees, D., Fahrutdinova, A., Guryanov, V., Fedorov, D., Korotyshkin, D., Forbes, J., Pogoreltsev, A., and Kürschner, D.: Semi-empirical model of middle atmosphere wind from the ground to the lower thermosphere, Adv. Space Res., 43, 239-246, https://doi.org/10.1016/j.asr.2008.05.011, 2009.

Kinoshita, T., Tomikawa, Y., and Sato, K.: On the ThreeDimensional Residual Mean Circulation and Wave Activity Flux of the Primitive Equations, J. Meteorol. Soc. Jpn. Ser. II, 88, 373 394, https://doi.org/10.2151/jmsj.2010-307, 2010.

Limpasuvan, V., Orsolini, Y. J., Chandran, A., Garcia, R. R., and Smith, A. K.: On the composite response of the MLT to major sudden stratospheric warming events with elevated stratopause, J. Geophys. Res.-Atmos., 121, 4518-4537, https://doi.org/10.1002/2015JD024401, 2016.

Livesey, N. J., Santee, M. L., and Manney, G. L.: A Matchbased approach to the estimation of polar stratospheric ozone loss using Aura Microwave Limb Sounder observations, Atmos. Chem. Phys., 15, 9945-9963, https://doi.org/10.5194/acp15-9945-2015, 2015.
Lübken, F.-J., Höffner, J., Viehl, T. P., Becker, E., Latteck, R., Kaifler, B., Murphy, D. J., and Morris, R. J.: Winter/summer transition in the Antarctic mesopause region, J. Geophys. Res.-Atmos., 120, 12394-12409, https://doi.org/10.1002/2015JD023928, 2015.

Manney, G. L., Krüger, K., Pawson, S., Minschwaner, K., Schwartz, M. J., Daffer, W. H., Livesey, N. J., Mlynczak, M. G., Remsberg, E. E., Russell, J. M., and Waters, J. W.: The evolution of the stratopause during the 2006 major warming: Satellite data and assimilated meteorological analyses, J. Geophys. Res., 113, D11115, https://doi.org/10.1029/2007JD009097, 2008.

Manson, A. H. and Meek, C. E.: Climatologies of mean winds and tides observed by medium frequency radars at Troms $\varnothing\left(70^{\circ} \mathrm{N}\right)$ and Saskatoon $\left(52^{\circ} \mathrm{N}\right)$ during 1987-1989, Can. J. Phys., 69, 966-975, https://doi.org/10.1139/p91-152, 1991.

Matsuno, T.: A dynamical model of the stratospheric sudden warming, J. Atmos. Sci. 28, 1479-1494, https://doi.org/10.1175/1520 0469(1971)028<1479:ADMOTS>2.0.CO;2, 1971.

Matthias, V., Hoffmann, P., Rapp, M., and Baumgarten, G.: Composite analysis of the temporal development of waves in the polar $\{$ MLT\} region during stratospheric warmings, J. Atmos. Sol.-Terr. Phy., 90-91, 86-96, https://doi.org/10.1016/j.jastp.2012.04.004, 2012.

Matthias, V., Hoffmann, P., Manson, A., Meek, C., Stober, G., Brown, P., and Rapp, M.: The impact of planetary waves on the latitudinal displacement of sudden stratospheric warmings, Ann. Geophys., 31, 1397-1415, https://doi.org/10.5194/angeo31-1397-2013, 2013.

Matthias, V., Dörnbrack, A., and Stober, G.: The extraordinarily strong and cold polar vortex in the early northern winter 2015/2016, Geophys. Res. Lett., 43, 12287-12294, https://doi.org/10.1002/2016GL071676, 2016.

McCormack, J., Hoppel, K., Kuhl, D., de Wit, R., Stober, G., Espy, P., Baker, N., Brown, P., Fritts, D., Jacobi, C., Janches, D., Mitchell, N., Ruston, B., Swadley, S., Viner, K., Whitcomb, T., and Hibbins, R.: Comparison of mesospheric winds from a high-altitude meteorological analysis system and meteor radar observations during the boreal winters of 2009/2010 and 2012/2013, J. Atmos. Sol.-Terr. Phy., https://doi.org/10.1016/j.jastp.2016.12.007, 2016.

Picone, J. M., Hedin, A. E., Drob, D. P., and Aikin, A. C.: NRLMSISE-00 empirical model of the atmosphere: Statistical comparisons and scientific issues, J. Geophys. Res.-Space, 107 1468, https://doi.org/10.1029/2002JA009430, 2002.

Scherhag, R.: Die explosionsartige Stratosphärenerwärmung des Spätwinters 1951/52, Ber. Deut. Wetterdienst, 38, 51-63, 1952.

Schwartz, M., Lambert, A., Manney, G., Read, W., Livesey, N., Froidevaux, L., Ao, C., Bernath, P., Boone, C., Cofield, R., Daffer, W., Drouin, B., Fetzer, E., Fuller, R., Jarnot, R., Jiang, J., Jiang, Y., Knosp, B. W., Krüger, K., Li, J.L., Mlynczak, M., Pawson, S., Russell, J., Santee, M., Snyder, W., Stek, P., Thurstans, R., Tompkins, A., Wagner, P., Walker, K., Waters, J. W., and Wu, D. L.: Validation of the Aura Microwave Limb Sounder temperature and geopotential height measurements, J. Geophys. Res.-Atmos., 113, d15S11, https://doi.org/10.1029/2007JD008783, 2008. 
Singer, W., Latteck, R., Millan, L. F., Mitchell, N. J., and Fiedler, J.: Radar Backscatter from Underdense Meteors and Diffusion Rates, 403-409, Springer New York, New York, NY, https://doi.org/10.1007/978-0-387-78419-9_56, 2008.

Stober, G., Jacobi, C., Fröhlich, K., and Oberheide, J.: Meteor radar temperatures over Collm $\left(51.3^{\circ} \mathrm{N}, 13^{\circ} \mathrm{E}\right)$, Adv. Space Res., 42, 1253-1258, https://doi.org/10.1016/j.asr.2007.10.018, 2008.

Stober, G., Jacobi, C., Matthias, V., Hoffmann, P., and Gerding, M.: Neutral air density variations during strong planetary wave activity in the mesopause region derived from meteor radar observations, J. Atmos. Sol.-Terr. Phy., 74, 55-63, https://doi.org/10.1016/j.jastp.2011.10.007, 2012.

Tsutsumi, M., Tsuda, T., Nakamura, T., and Fukao, S.: Temperature fluctuations near the mesopause inferred from meteor observations with the middle and upper atmosphere radar, Radio Sci., 29, 599-610, https://doi.org/10.1029/93RS03590, 1994.

Viehl, T., Höffner, J., Lübken, F.-J., Plane, J., Kaifler, B., and Morris, R.: Summer time Fe depletion in the Antarctic mesopause region, J. Atmos. Sol.-Terr. Phy., 127, 97-102, https://doi.org/10.1016/j.jastp.2015.04.013, 2015.
Waters, J. W., Froidevaux, L., Harwood, R. S., Jarnot, R. F., Pickett, H. M., Read, W. G., Siegel, P. H., Cofield, R. E., Filipiak, M. J., Flower, D. A., Holden, J. R., Lau, G. K., Livesey, N. J., Manney, G. L., Pumphrey, H. C., Santee, M. L., Wu, D. L., Cuddy, D. T., Lay, R. R., Loo, M. S., Perun, V. S., Schwartz, M. J., Stek, P. C., Thurstans, R. P., Boyles, M. A., Chandra, K. M., Chavez, M. C., Chen, G.-S., Chudasama, B. V., Dodge, R., Fuller, R. A., Girard, M. A., Jiang, J. H., Jiang, Y., Knosp, B. W., LaBelle, R. C., Lam, J. C., Lee, K. A., Miller, D., Oswald, J. E., Patel, N. C., Pukala, D. M., Quintero, O., Scaff, D. M., Snyder, W. V., Tope, M. C., Wagner, P. A., and Walch, M. J.: The Earth observing system microwave limb sounder (EOS MLS) on the aura Satellite, IEEE T. Geosci. Remote Sens., 44, 1075-1092, https://doi.org/10.1109/TGRS.2006.873771, 2006.

Xu, X., Manson, A. H., Meek, C. E., Jacobi, C., Hall, C. M., and Drummond, J. R.: Verification of the mesospheric winds within the Canadian Middle Atmosphere Model Data Assimilation System using radar measurements, J. Geophys. Res.-Atmos., 116, d16108, https://doi.org/10.1029/2011JD015589, 2011. 